\title{
Splanchnic metabolism of nutrients and hormones in steers fed alfalfa under conditions of increased absorption of ammonia and L-arginine supply across the portal-drained viscera
}

Article

Accepted Version

Maltby, S. A., Reynolds, C. K., Lomax, M. A. and Beever, D. E. (2005) Splanchnic metabolism of nutrients and hormones in steers fed alfalfa under conditions of increased absorption of ammonia and L-arginine supply across the portal-drained viscera. Journal of Animal Science, 83 (5). pp. 10088-1096. ISSN 0021-8812 doi: https://doi.org/10.2527/2005.8351088x Available at https://centaur.reading.ac.uk/89404/

It is advisable to refer to the publisher's version if you intend to cite from the work. See Guidance on citing.

To link to this article DOI: http://dx.doi.org/10.2527/2005.8351088x

Publisher: American Society of Animal Science

All outputs in CentAUR are protected by Intellectual Property Rights law, including copyright law. Copyright and IPR is retained by the creators or other copyright holders. Terms and conditions for use of this material are defined in the End User Agreement. 


\section{www.reading.ac.uk/centaur}

\section{CentAUR}

Central Archive at the University of Reading

Reading's research outputs online 


\title{
Splanchnic metabolism of nutrients and hormones in steers fed alfalfa under conditions of increased absorption of ammonia and L-arginine supply across the portal-drained viscera ${ }^{1,2,3}$
}

\author{
S. A. Maltby ${ }^{\dagger}$ C. K. Reynolds ${ }^{* 4}$, M. A. Lomax $\dagger^{5}$ and D. E. Beever $\ddagger^{6}$ \\ *USDA, ARS, Beltsville, MD 20705; †Department of Biochemistry and Physiology, The University of Reading, \\ Whiteknights, Reading, RG6 2AJ, U.K.; and $\ddagger$ School of Agriculture, Policy and Development, \\ The University of Reading, Earley Gate, Reading, RG6 6AR, U.K.
}

\begin{abstract}
Effects of increased ammonia and/or arginine absorption on net splanchnic (portal-drained viscera [PDV] plus liver) metabolism of nonnitrogenous nutrients and hormones in cattle were examined. Six Hereford $\times$ Angus steers (501 $\pm 1 \mathrm{~kg} \mathrm{BW})$ prepared with vascular catheters for measurements of net flux across the splanchnic bed were fed a $75 \%$ alfalfa:25\% (as-fed basis) corn and soybean meal diet (0.523 $\mathrm{MJ}$ of ME/[kg $\left.\left.\mathrm{BW}^{0.75} \cdot \mathrm{d}\right]\right)$ every $2 \mathrm{~h}$ without $(27.0 \mathrm{~g}$ of $\mathrm{N} / \mathrm{kg}$ of $\mathrm{DM})$ and with $20 \mathrm{~g}$ of urea/ $/ \mathrm{kg}$ of DM ( $35.7 \mathrm{~g}$ of N/ $\mathrm{kg}$ of DM) in a split-plot design. Net flux measurements were made immediately before and after a 72 -h mesenteric vein infusion of $\mathrm{L}$-arginine $(15 \mathrm{mmol} / \mathrm{h})$. There were no treatment effects on PDV or hepatic $\mathrm{O}_{2}$ consumption. Dietary urea had no effect on splanchnic metabolism of glucose or L-lactate, but arginine infusion decreased net hepatic removal of L-lactate when urea was fed $(P<0.01)$. Net
\end{abstract}

PDV appearance of n-butyrate was increased by arginine infusion $(P<0.07)$, and both dietary urea $(P<$ $0.09)$ and arginine infusion $(P<0.05)$ increased net hepatic removal of n-butyrate. Dietary urea also increased total splanchnic acetate output $(P<0.06)$, tended to increase arterial glucagon concentration $(P$ $<0.11)$, and decreased arterial ST concentration $(P<$ 0.03). Arginine infusion increased arterial concentration $(P<0.07)$ and net PDV release $(P<0.10)$ and tended to increase hepatic removal $(P<0.11)$ of insulin, as well as arterial concentration $(P<0.01)$ and total splanchnic output $(P<0.01)$ of glucagon. Despite changes in splanchnic $\mathrm{N}$ metabolism, increased ammonia and arginine absorption had little measurable effect on splanchnic metabolism of glucose and other nonnitrogenous components of splanchnic energy metabolism.

Key Words: Arginine, Bovidae, Energy, Hormones, Liver, Urea

(C)2005 American Society of Animal Science. All rights reserved.

J. Anim. Sci. 2005. 83:1088-1096

\section{Introduction}

Ruminants typically absorb little or no glucose across the portal-drained viscera (PDV) and therefore depend on hepatic glucose synthesis to meet glucose requirements (Bergman, 1990). In compensation, ruminants absorb substantial quantities of propionate, the pre-

\footnotetext{
${ }^{1}$ Mention of a trade name, proprietary product, or specific equipment does not constitute a guarantee or warranty by the USDA and does not imply its approval to the exclusion of other products that may be suitable.

${ }^{2}$ The authors acknowledge student sponsorship for S. A. Maltby from the U.K. Science and Education Research Council.

${ }^{3}$ The authors gratefully acknowledge the invaluable assistance of the Beltsville Agric. Res. Center Veterinary Services and Animal Operations for animal care; D. Hucht, M. L. Miner, S. Thurber, and B. Morgan for help in obtaining and analyzing samples, and the former AFRC Inst. for Grassl. and Environ. Res. Analytical Services at Hurley, U.K., for VFA analyses.
}

dominant gluconeogenic precursor, as well as L-lactate and AA, which also supply carbon for glucose synthesis. Metabolic pathways of gluconeogenesis share many common intermediates, enzymes, and transporters with those required for ureagenesis; thus, the two pathways are inherently interactive (Meijer et al., 1978). In vitro work with ruminant hepatocytes has indicated inhibition of glucose synthesis associated with high rates of ureagenesis (Demigne et al., 1992), whereas in

\footnotetext{
${ }^{4}$ Correspondence and current address: Dept. of Anim. Sci., The Ohio State Univ., OARDC, 1680 Madison Ave., Wooster 44691-4096 (phone: 330-263-3793; fax: 330-263-3949; e-mail: Reynolds.345@ osu.edu).

${ }^{5}$ Current address: Dept. of Agric. Sci., Imperial College, Wye, Kent TN25 5AH, U.K.

${ }^{6}$ Current address: Richard Keenan \& Co., Borris, Co. Carlow, Ireland.

Received April 21, 2004.

Accepted January 25, 2005.
} 
vivo studies have demonstrated effects of feeding urea, to increase ammonia absorption, on plasma glucose concentration or metabolism in ruminants (Prior et al., 1972; Spires and Clark, 1979). Effects of increased ammonia absorption on glucose metabolism may be due in part to effects on insulin metabolism (Visek, 1984; Fernandez et al., 1990). In addition, the energetic costs of urea synthesis have been suggested to account for a substantial portion of hepatic $\mathrm{O}_{2}$ consumption (Milano et al., 2000), but the effects of increased ammonia absorption on hepatic $\mathrm{O}_{2}$ uptake, and the net energy costs of urea synthesis, are equivocal. Our study was designed to increase hepatic urea synthesis by feeding urea to increase ammonia absorption and by increasing the absorption of arginine, a positive activator and cytosolic intermediate of the urea cycle, via mesenteric vein infusion. Arginine also is a potent secretagogue for a number of glucoregulatory hormones (Kuhara et al., 1991). Our objective was to determine the effects of these treatments on splanchnic $\mathrm{O}_{2}$ consumption and metabolism of nutrients and hormones. Effects of these treatments on splanchnic metabolism of nitrogenous compounds and urinary $\mathrm{N}$ excretion are reported in an accompanying paper (Maltby et al., 2005).

\section{Materials and Methods}

Details of the materials and methods for this experiment have been reported in full in an accompanying article (Maltby et al., 2005). This study was conducted with the approval of the USDA Beltsville Agricultural Research Center Animal Care Committee. In brief, six Hereford $\times$ Angus steers (501 $\pm 1 \mathrm{~kg} \mathrm{BW})$ prepared with chronic indwelling catheters for measurement of net nutrient flux across the PDV and liver (total splanchnic tissues) were fed a pelleted $75 \%$ alfalfa:25\% corn and soybean meal (as-fed basis) diet (0.523 MJ of ME/[kg $\left.\mathrm{BW}^{0.75} \cdot \mathrm{d}\right]$ ) alone or with an additional $20 \mathrm{~g}$ of urea/kg of DM. The diets were offered in 12 equal portions at 2 -h intervals, and each dietary period was of $4 \mathrm{wk}$ duration. Initially, six consecutive hourly blood samples were taken simultaneously from the portal and hepatic veins and artery during a primed, continuous mesenteric vein infusion of $\rho$-aminohippuric acid for measurement of blood flow. After this, a 72-h mesenteric vein infusion $(28.2 \mathrm{~mL} / \mathrm{h})$ of L-arginine hydrochloride $(0.5315$ $\mathrm{mol} / \mathrm{L}, \mathrm{pH} 7.4$ ) was initiated. Following $66 \mathrm{~h}$ of arginine infusion, $\rho$-aminohippuric acid was infused simultaneously with the arginine, and a second set of six blood samples was taken at hourly intervals over the last 5 $\mathrm{h}$ of arginine infusion.

Hourly blood samples were analyzed for blood and plasma $\rho$-aminohippuric acid and for blood $\mathrm{O}_{2}$ concentration as described by Reynolds et al. (1991a). Plasma L-lactate and glucose concentrations were measured on pooled aliquots from hourly plasma samples (Reynolds et al., 1991a), and blood VFA concentrations were determined on pooled aliquots from hourly blood samples deproteinized and neutralized according to the methods of Seal et al. (1992). $\beta$-Hydroxybutyrate (BOHB) concentrations were measured enzymatically on pooled aliquots of hourly blood samples deproteinized and neutralized as described previously (Reynolds et al., 1991a). Additional blood samples were taken at 20-min intervals, and along with the hourly samples, were used for measurement of plasma insulin, glucagon, and $\rho$ aminohippuric acid concentrations (Reynolds et al., 1989). Somatotropin concentrations were determined on pooled hourly plasma samples according to the methods reported by Reynolds et al. (1989). Plasma flow rates used in the calculation of net flux of insulin and glucagon were a mean of the 16 individual flow rates, but because ST was determined on pooled samples, flow rates used in ST flux calculations were the mean hourly values.

The data were analyzed as a split-plot and least squares means were generated using the GLM procedure of SAS (SAS Inst., Inc., Cary, NC). Whole-plot effects of period, steer, and diet were tested against the error mean square for their interaction. Subplot period (arginine infusion) and diet $\times$ arginine infusion interaction were tested using the residual error mean square. Data analyzed were mean concentrations and net visceral fluxes for the six animals on each treatment. A positive net flux represents a net release, whereas a negative value represents a net removal or uptake of a nutrient or hormone by the tissue. In addition, hepatic extraction of metabolites as a percentage of their total vascular supply to the liver, and the maximum potential net contribution of glucose precursors removed by the liver to glucose released by the liver, were calculated (Reynolds et al., 1991a). For all data, $P<0.10$ was considered to be a significant difference.

\section{Results}

\section{Blood Flow}

As reported previously by Maltby et al. (2005), there were no significant effects of either urea or arginine treatment on blood flow rate, but feeding urea decreased $(P<0.05)$ average hourly hepatic plasma flow (Table 1). A numerical decrease in hepatic blood flow when urea was fed was not significant $(P=0.17)$, and when the additional plasma flow rates, measured at 20min intervals for the calculation of insulin and glucagon fluxes (Table 1), were included, the effect of urea feeding on hepatic plasma flow also was not significant. However, arginine infusion increased both portal $(P<0.08)$ and hepatic $(P<0.01)$ plasma flow rate when measurements made at 20 -min intervals were statistically analyzed.

\section{Nutrients}

Arterial concentrations of nutrients measured (Table 2) were not affected by urea addition, but arterial concentrations of $\mathrm{O}_{2}$ and L-lactate were decreaed by argi- 
Table 1. Portal and hepatic blood and plasma flow rates in beef steers fed a $75 \%$ alfalfa diet without or with $2 \%$ urea immediately before starting (-Arg) and ending (+Arg) a 72-h mesenteric vein infusion of L-arginine

\begin{tabular}{|c|c|c|c|c|c|c|c|c|}
\hline \multirow[b]{2}{*}{ Item } & \multicolumn{2}{|c|}{ Alfalfa diet } & \multicolumn{2}{|c|}{$2 \%$ Urea diet } & \multirow[b]{2}{*}{ SEM } & \multicolumn{3}{|c|}{$P$-value ${ }^{\text {a }}$} \\
\hline & $-\operatorname{Arg}$ & $+\operatorname{Arg}$ & $-\operatorname{Arg}$ & $+\mathrm{Arg}$ & & Diet & Arg & $\mathrm{D} \times \mathrm{A}$ \\
\hline No. of observations & 6 & 5 & 6 & 6 & & & & \\
\hline \multicolumn{9}{|l|}{ Blood flow, $\mathrm{L} / \mathrm{h}^{2}$} \\
\hline Portal vein & 673 & 723 & 679 & 694 & 31 & 0.684 & 0.260 & 0.536 \\
\hline Hepatic & 788 & 799 & 758 & 763 & 26 & 0.164 & 0.738 & 0.898 \\
\hline \multicolumn{9}{|c|}{ Hourly plasma flow, L/h ${ }^{b}$} \\
\hline Portal & 463 & 501 & 460 & 478 & 18 & 0.476 & 0.117 & 0.558 \\
\hline Hepatic & 544 & 561 & 513 & 523 & 20 & 0.049 & 0.453 & 0.855 \\
\hline \multicolumn{9}{|l|}{ Plasma flow, $\mathrm{L} / \mathrm{h}^{\mathrm{c}}$} \\
\hline Portal vein & 450 & 504 & 452 & 463 & 18 & 0.429 & 0.074 & 0.207 \\
\hline Hepatic & 530 & 566 & 508 & 516 & 22 & 0.102 & 0.002 & 0.649 \\
\hline
\end{tabular}

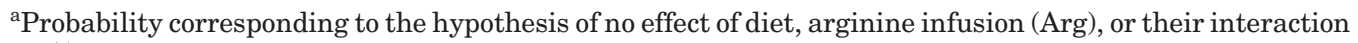
$(\mathrm{D} \times \mathrm{A})$.

${ }^{\mathrm{b}}$ Mean of six measurements at 60 -min intervals.

${ }^{\mathrm{c}}$ Mean of 16 measurements at 20 -min intervals.

nine infusion $(P<0.01)$. Mesenteric vein infusion of arginine increased arterial concentration of n-butyrate when the control diet was fed, but not when urea was fed (diet $\times$ arginine interaction; $P<0.09$ ). In addition, there was a diet $\times$ arginine infusion interaction for arterial glucose concentration $(P<0.06)$, which was increased by arginine infusion when urea was fed.

Diet had little effect on net splanchnic flux of most nutrients (Table 2). Feeding urea did increase net hepatic removal of n-butyrate $(P<0.09)$ and total splanchnic release of acetate $(P<0.06)$, as well as hepatic extraction of $n$-butyrate $(P<0.01)$ as a percentage of total supply. Similarly, arginine infusion had little effect on net splanchnic flux rates measured, but it increased net PDV absorption $(P<0.07)$, hepatic removal $(P<0.05)$, and hepatic extraction $(P<0.08)$ of n-butyrate. In addition, net hepatic removal and hepatic extraction of L-lactate was increased by arginine infusion when the control diet was fed and decreased by arginine infusion when urea was fed (diet $\times$ arginine infusion interaction; $P<0.01$ ); therefore, total splanchnic release of lactate was decreased by arginine infusion when the control diet was fed and increased by arginine infusion when urea was fed (diet $\times$ arginine infusion interaction; $P<0.01)$.

\section{Hormones}

Feeding urea decreased arterial concentration of ST $(P<0.04)$ and tended to increase arterial concentration of glucagon $(P<0.11)$, but it had no effect on arterial insulin $(P=0.57$; Table 3$)$. Arginine infusion increased arterial insulin $(P<0.07)$ and glucagon $(P<0.01)$ concentration, but it had no effect on ST concentration. Feeding urea had no effect on the net PDV release, hepatic removal, or total splanchnic output of either insulin or glucagon (Table 3). Urea addition switched the net PDV flux of ST from a net removal to a net output $(P<0.04)$, although venous-arterial concentra- tion differences for ST did not differ from zero (data not shown). Arginine infusion also increased net PDV release $(P<0.10)$ and tended to increase net hepatic removal $(P<0.11)$ of insulin, such that the overall effect on total splanchnic insulin output was small and not significant $(P=0.52)$. Total splanchnic output of glucagon was greater when arginine was infused $(P<0.01)$, and this occurred to a greater extent on the urea-supplemented diet (diet $\times$ arginine interaction; $P<0.03$ ). These changes in total splanchnic glucagon output were due to numerical changes in net PDV release and hepatic removal of glucagon when arginine was infused.

\section{Discussion}

\section{Blood and Plasma Flow}

Reasons for the increase in liver plasma flow resulting from arginine infusion are uncertain. Similar studies have shown mesenteric vein infusion of L-alanine decreased liver blood and plasma flow in beef heifers (Reynolds and Tyrrell, 1991b), whereas mesenteric vein infusion of L-ornithine increased both liver and PDV blood and plasma flow (Reynolds and Hucht, 1994). These changes in blood flow were relatively small and occurred without any change in diet intake, a principal determinant of splanchnic blood flow (Reynolds et al., 1991b).

\section{Nutrients and Oxygen}

The decrease in arterial $\mathrm{O}_{2}$ concentration (Table 2) can be attributed to the decrease in packed cell volume reported in the accompanying paper (Maltby et al., 2005). There was very little effect of either diet or arginine infusion on the net metabolism of nonnitrogenous nutrients or $\mathrm{O}_{2}$ by tissues of the PDV. As expected, there was a net utilization of glucose across the PDV, but a net appearance of VFA, L-lactate, and BOHB. 
Table 2. Arterial concentration, net splanchnic flux and hepatic extraction of blood oxygen, volatile fatty acids, and $\beta$-hydroxybutyrate and plasma L-lactate and glucose in beef steers fed a $75 \%$ alfalfa diet without or with $2 \%$ urea immediately before starting (-Arg) and ending (+Arg) a 72-h mesenteric vein infusion of L-arginine ${ }^{\mathrm{a}}$

\begin{tabular}{|c|c|c|c|c|c|c|c|c|}
\hline \multirow[b]{2}{*}{ Item } & \multicolumn{2}{|c|}{ Alfalfa diet } & \multicolumn{2}{|c|}{$2 \%$ Urea diet } & \multirow[b]{2}{*}{ SEM } & \multicolumn{3}{|c|}{$P$-value ${ }^{b}$} \\
\hline & $-\operatorname{Arg}$ & $+\operatorname{Arg}$ & $-\operatorname{Arg}$ & $+\operatorname{Arg}$ & & Diet & Arg & $\mathrm{D} \times \mathrm{A}$ \\
\hline No. of observations & 6 & 5 & 6 & 6 & & & & \\
\hline \multicolumn{9}{|c|}{ Arterial concentration, $\mathrm{m} M$} \\
\hline Oxygen & 6.100 & 5.664 & 6.179 & 5.884 & 0.095 & 0.487 & 0.002 & 0.426 \\
\hline Acetate & 1.987 & 1.886 & 1.983 & 1.929 & 0.068 & 0.727 & 0.234 & 0.708 \\
\hline Propionate & 0.032 & 0.027 & 0.030 & 0.030 & 0.002 & 0.944 & 0.341 & 0.233 \\
\hline n-Butyrate & 0.013 & 0.018 & 0.013 & 0.013 & 0.002 & 0.134 & 0.076 & 0.084 \\
\hline i-Butyrate & 0.005 & 0.004 & 0.006 & 0.004 & 0.001 & 0.878 & 0.254 & 0.664 \\
\hline$\beta$-Hydroxybutyrate & 0.434 & 0.455 & 0.475 & 0.443 & 0.022 & 0.691 & 0.775 & 0.200 \\
\hline L-Lactate & 0.547 & 0.474 & 0.563 & 0.509 & 0.016 & 0.267 & 0.005 & 0.592 \\
\hline Glucose & 3.428 & 3.409 & 3.433 & 3.535 & 0.027 & 0.226 & 0.176 & 0.059 \\
\hline \multicolumn{9}{|c|}{ Portal-drained visceral flux, $\mathrm{mmol} / \mathrm{h}$} \\
\hline Oxygen & $-1,002$ & -968 & -986 & -973 & 44 & 0.855 & 0.561 & 0.801 \\
\hline Acetate & 413 & 409 & 481 & 476 & 24 & 0.160 & 0.845 & 0.964 \\
\hline Propionate & 198 & 196 & 213 & 210 & 13 & 0.190 & 0.830 & 0.946 \\
\hline n-Butyrate & 31 & 37 & 36 & 38 & 2 & 0.232 & 0.070 & 0.335 \\
\hline i-Butyrate & 14 & 12 & 13 & 15 & 2 & 0.847 & 0.870 & 0.338 \\
\hline$\beta$-Hydroxybutyrate & 86 & 86 & 90 & 91 & 4 & 0.336 & 0.915 & 0.926 \\
\hline L-Lactate & 58 & 54 & 54 & 54 & 4 & 0.605 & 0.492 & 0.523 \\
\hline Glucose & -26 & -14 & -24 & -16 & 16 & 0.977 & 0.498 & 0.901 \\
\hline \multicolumn{9}{|l|}{ Hepatic flux, mmol/h } \\
\hline Oxygen & -926 & -870 & -947 & -929 & 39 & 0.457 & 0.319 & 0.602 \\
\hline Acetate & 120 & 102 & 106 & 78 & 21 & 0.716 & 0.239 & 0.787 \\
\hline Propionate & -180 & -179 & -198 & -196 & 11 & 0.189 & 0.885 & 0.998 \\
\hline n-Butyrate & -23 & -30 & -29 & -31 & 2 & 0.087 & 0.043 & 0.385 \\
\hline i-Butyrate & -14 & -13 & -14 & -16 & 2 & 0.248 & 0.739 & 0.443 \\
\hline$\beta$-Hydroxybutyrate & 84 & 75 & 78 & 68 & 9 & 0.455 & 0.308 & 0.951 \\
\hline L-Lactate & -30 & -44 & -32 & -27 & 2 & 0.333 & 0.040 & 0.001 \\
\hline Glucose & 143 & 148 & 148 & 145 & 14 & 0.978 & 0.955 & 0.765 \\
\hline \multicolumn{9}{|c|}{ Total splanchnic flux, $\mathrm{mmol} / \mathrm{h}$} \\
\hline Oxygen & $-1,928$ & $-1,839$ & $-1,933$ & $-1,902$ & 46 & 0.568 & 0.178 & 0.500 \\
\hline Acetate & 532 & 511 & 587 & 554 & 28 & 0.052 & 0.297 & 0.811 \\
\hline Propionate & 18 & 17 & 15 & 13 & 2 & 0.302 & 0.605 & 0.677 \\
\hline n-Butyrate & 7 & 7 & 8 & 7 & 1 & 0.954 & 0.689 & 0.532 \\
\hline i-Butyrate & 1 & 0 & -1 & -1 & 1 & 0.664 & 0.737 & 0.582 \\
\hline$\beta$-Hydroxybutyrate & 169 & 161 & 167 & 159 & 10 & 0.738 & 0.454 & 0.990 \\
\hline L-Lactate & 29 & 11 & 22 & 28 & 4 & 0.348 & 0.126 & 0.010 \\
\hline Glucose & 118 & 134 & 124 & 129 & 11 & 0.969 & 0.304 & 0.571 \\
\hline \multicolumn{9}{|l|}{ Hepatic extraction, $\%$} \\
\hline Propionate & 80.7 & 82.0 & 84.0 & 84.4 & 0.8 & 0.109 & 0.290 & 0.548 \\
\hline n-Butyrate & 57.4 & 58.1 & 62.1 & 65.4 & 1.2 & 0.006 & 0.078 & 0.225 \\
\hline i-Butyrate & 73.5 & 80.9 & 79.7 & 88.4 & 4.4 & 0.789 & 0.967 & 0.415 \\
\hline L-Lactate & 8.6 & 14.1 & 9.7 & 9.0 & 0.6 & 0.425 & 0.003 & 0.001 \\
\hline
\end{tabular}

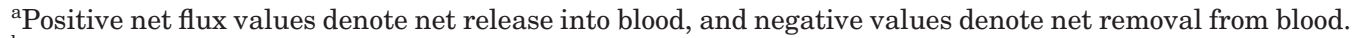

${ }^{b}$ Probability corresponding to the hypothesis of no effect of diet, arginine infusion (Arg), or their interaction $(\mathrm{D} \times \mathrm{A})$

Addition of urea to the control alfalfa diet tended to increase the net PDV appearance of total VFA $(P<$ $0.14 ; 655 \mathrm{vs} .741 \mathrm{mmol} / \mathrm{h}$ ), suggesting that feeding urea affected the pattern of microbial fermentation in the rumen and/or VFA absorption in these steers fed every $2 \mathrm{~h}$. In other studies, feeding urea increased total VFA concentrations in the rumen (Bruggemann and Giesecke, 1967; Chalupa et al., 1970). The increase in net PDV release of VFA was the result of a nonsignificant increase in the net release of each individual VFA, but most notably a $16 \%$ increase in acetate absorption.
These results may have been due to a change in the pattern of ruminal fermentation or a decrease in PDV utilization of acetate. Despite a nonsignificant decrease in hepatic acetate production on the urea-supplemented diet, the total splanchnic output of acetate was significantly higher when urea was fed.

Net PDV appearance of n-butyrate increased with arginine infusion (Table 2). The cause of this increase is unclear, but it may be related to a repartitioning of substrates used for oxidative metabolism by the PDV, possibly as a result of increases in arterial insulin con- 
Table 3. Arterial concentration, net splanchnic flux, and hepatic extraction of plasma insulin, glucagon, and somatotropin in beef steers fed a $75 \%$ alfalfa diet without or with $2 \%$ urea immediately before starting $(-\mathrm{Arg})$ and ending $(+\mathrm{Arg})$ a $72-\mathrm{h}$ mesenteric vein infusion of L-arginine

\begin{tabular}{|c|c|c|c|c|c|c|c|c|}
\hline \multirow[b]{2}{*}{ Item } & \multicolumn{2}{|c|}{ Alfalfa diet } & \multicolumn{2}{|c|}{$2 \%$ Urea diet } & \multirow[b]{2}{*}{ SEM } & \multicolumn{3}{|c|}{$P$-value ${ }^{\mathrm{a}}$} \\
\hline & $-\operatorname{Arg}$ & + Arg & - Arg & + Arg & & Diet & Arg & $\mathrm{D} \times \mathrm{A}$ \\
\hline No. of observations & 6 & 5 & 6 & 6 & & & & \\
\hline \multicolumn{9}{|c|}{ Arterial concentration, $\mathrm{m} M$} \\
\hline Insulin & 0.086 & 0.115 & 0.103 & 0.114 & 0.009 & 0.557 & 0.065 & 0.454 \\
\hline Glucagon & 0.114 & 0.131 & 0.128 & 0.150 & 0.004 & 0.102 & 0.002 & 0.649 \\
\hline Somatotropin & 0.135 & 0.172 & 0.104 & 0.101 & 0.014 & 0.024 & 0.267 & 0.212 \\
\hline \multicolumn{9}{|c|}{ Portal-drained visceral flux, $\mathrm{mmol} / \mathrm{h}$} \\
\hline Insulin & 20.1 & 23.5 & 19.2 & 24.1 & 2.1 & 0.975 & 0.092 & 0.651 \\
\hline Glucagon & 47.0 & 70.9 & 50.9 & 58.2 & 140.0 & 0.811 & 0.315 & 0.586 \\
\hline Somatotropin & -10.7 & -28.7 & 11.1 & 7.3 & 13.7 & 0.033 & 0.468 & 0.633 \\
\hline \multicolumn{9}{|l|}{ Hepatic flux, $\mathrm{mmol} / \mathrm{h}$} \\
\hline Insulin & -10.3 & -11.7 & -7.9 & -12.1 & 1.7 & 0.610 & 0.101 & 0.648 \\
\hline Glucagon & -41.9 & -63.3 & -44.2 & -45.8 & 14.3 & 0.704 & 0.461 & 0.526 \\
\hline Somatotropin & -4.9 & 7.7 & -14.9 & -9.8 & 10.5 & 0.219 & 0.445 & 0.741 \\
\hline \multicolumn{9}{|c|}{ Total splanchnic flux, $\mathrm{mmol} / \mathrm{h}$} \\
\hline Insulin & 9.8 & 11.8 & 11.3 & 12.0 & 1.2 & 0.328 & 0.503 & 0.900 \\
\hline Glucagon & 5.1 & 7.6 & 6.7 & 12.4 & 0.5 & 0.175 & 0.001 & 0.023 \\
\hline Somatotropin & -15.6 & -21.0 & -3.7 & -2.5 & 9.6 & 0.177 & 0.840 & 0.748 \\
\hline \multicolumn{9}{|c|}{ Hepatic extraction, $\%$} \\
\hline Insulin & 13.8 & 12.6 & 8.9 & 13.3 & 1.8 & 0.332 & 0.354 & 0.197 \\
\hline Glucagon & 28.0 & 20.3 & 30.1 & 27.8 & 5.6 & 0.677 & 0.417 & 0.655 \\
\hline
\end{tabular}

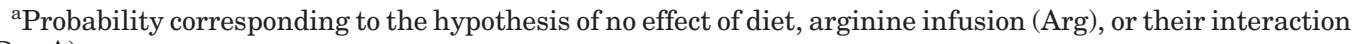
$(\mathrm{D} \times \mathrm{A})$.

centration (Table 3). n-Butyrate is extensively metabolized by the ruminal epithelium to BOHB, but also to acetoacetate, carbon dioxide, and some AA (Bergman, 1990); however, there was no associated decrease in net PDV flux of BOHB to suggest a decrease in n-butyrate metabolism to BOHB. The increase in n-butyrate supply to the liver due to both feeding urea and arginine infusion was matched by a concomitant increase in hepatic removal of n-butyrate. When Reynolds et al. (1992b) infused n-butyrate into a mesenteric vein, the resulting increase in hepatic n-butyrate removal was accompanied by an equivalent increase in hepatic $\mathrm{BOHB}$ release. However, in the present study the metabolic fate of the additional n-butyrate removed is unclear because there was no apparent change in hepatic BOHB flux. It is possible there was an increase in hepatic acetoacetate production from n-butyrate but not the subsequent conversion to BOHB due to limiting cytosolic NADH.

Previous studies have shown hepatic glucose synthesis to be directly correlated to ME intake and glucose requirement (Reynolds et al., 1991a). In the present study, there was no apparent effect of urea supplementation on net glucose release by the liver, which suggests that despite a considerable increase in hepatic urea synthesis, there was no evidence of any inhibition of gluconeogenesis. In contrast, in vitro studies with both isolated rat hepatocytes (Meijer et al., 1978; Krebs et al., 1979) and sheep hepatocytes (Demigne et al., 1991) indicated that due to the shared requirement for many metabolic intermediates, reducing power, and
ATP, high rates of urea synthesis inhibited glucose synthesis. Although in vivo studies have shown that feeding urea decreases plasma glucose concentrations in sheep (Prior et al., 1972), the effect was not evident when urea was fed more frequently (Prior, 1976). In our study, steers were fed every $2 \mathrm{~h}$, which reduced postprandial surges of ammonia absorption and may have facilitated metabolic compensations to increased ammonia absorption and ureagenesis. Regardless, it does not seem that increased ammonia absorption resulting from frequent urea feeding decreases net hepatic release of glucose in mature steers fed at near maintenance ME intakes. Similarly, mesenteric vein infusion of ammonia did not change net glucose flux across the liver of sheep (Milano et al., 2000). Waterlow (1999) concluded that even maximal rates of urea synthesis would have no effect on liver gluconeogenesis.

The marked increases in hepatic urea production attributable to increased ammonia and arginine absorption in the present study were not accompanied by changes in liver $\mathrm{O}_{2}$ consumption. This finding agrees with a previous study in beef cattle where diet-induced changes in ammonia absorption and hepatic urea production were not accompanied by changes in hepatic $\mathrm{O}_{2}$ consumption, but in the previous study, changes in ammonia absorption and hepatic urea production were a result of substantial changes in diet composition and nutrient metabolism (Reynolds et al., 1991a). In the present study, changes in hepatic ammonia removal and urea production were accompanied by minimal changes in hepatic metabolism of other nutrients; how- 
Table 4. The maximum potential contribution of precursors removed to hepatic glucose release $(\%)$ in beef steers fed a $75 \%$ alfalfa diet without or with $2 \%$ urea immediately before starting (-Arg) and ending (+Arg) a 72-h mesenteric vein infusion of L-arginine

\begin{tabular}{|c|c|c|c|c|c|c|c|c|}
\hline \multirow[b]{2}{*}{ Item } & \multicolumn{2}{|c|}{ Alfalfa diet } & \multicolumn{2}{|c|}{$2 \%$ Urea diet } & \multirow[b]{2}{*}{ SEM } & \multicolumn{3}{|c|}{$P$-value ${ }^{\mathrm{a}}$} \\
\hline & $-\operatorname{Arg}$ & + Arg & $-\operatorname{Arg}$ & + Arg & & Diet & Arg & $\mathrm{D} \times \mathrm{A}$ \\
\hline Propionate & 63.2 & 68.1 & 68.1 & 69.2 & 9.2 & 0.371 & 0.721 & 0.820 \\
\hline L-Lactate & 10.3 & 15.2 & 10.5 & 9.0 & 1.4 & 0.200 & 0.204 & 0.026 \\
\hline Alanine & 6.7 & 7.3 & 6.7 & 6.0 & 1.3 & 0.508 & 0.985 & 0.571 \\
\hline Serine & 3.3 & 3.0 & 3.2 & 3.2 & 0.5 & 0.801 & 0.754 & 0.713 \\
\hline Threonine & 1.4 & 1.2 & 1.6 & 1.6 & 0.6 & 0.383 & 0.901 & 0.845 \\
\hline Glycine & 6.1 & 5.1 & 5.9 & 4.8 & 1.3 & 0.879 & 0.390 & 0.968 \\
\hline Glutamine & 4.8 & 5.1 & 4.0 & 7.0 & 1.3 & 0.555 & 0.201 & 0.297 \\
\hline Proline & 0.4 & 0.4 & 1.2 & 0.4 & 0.7 & 0.511 & 0.546 & 0.541 \\
\hline Asparagine & 4.6 & 2.9 & 3.2 & 3.3 & 0.9 & 0.302 & 0.383 & 0.289 \\
\hline Citrulline & 0.3 & - & 0.2 & 0.4 & 0.5 & 0.346 & 0.821 & 0.403 \\
\hline Valine & 0.3 & - & 1.4 & 0.6 & 10.0 & 0.320 & 0.259 & 0.767 \\
\hline Isoleucine & 0.2 & - & 0.5 & 0.3 & 0.5 & 0.529 & 0.555 & 0.919 \\
\hline Tyrosine & 2.0 & 1.3 & 1.7 & 1.9 & 0.4 & 0.598 & 0.404 & 0.226 \\
\hline Phenylalanine & 2.2 & 1.7 & 2.0 & 2.0 & 0.4 & 0.868 & 0.403 & 0.564 \\
\hline Ornithine & 0.1 & - & 0.8 & - & 0.4 & 0.770 & 0.001 & 0.226 \\
\hline Histidine & 1.0 & 0.5 & 0.9 & 1.0 & 0.3 & 0.609 & 0.432 & 0.359 \\
\hline Arginine & 0.8 & 4.1 & 1.8 & 6.8 & 0.9 & 0.130 & 0.002 & 0.295 \\
\hline Methionine & 0.7 & 0.5 & 0.7 & 0.8 & 0.2 & 0.330 & 0.816 & 0.227 \\
\hline Total AA & 35.7 & 32.6 & 35.8 & 42.5 & 60.0 & 0.499 & 0.812 & 0.527 \\
\hline Total & 109.2 & 98.5 & 112.6 & 118.4 & 9.1 & 0.130 & 0.832 & 0.490 \\
\hline
\end{tabular}

aProbability corresponding to the hypothesis of no effect of diet, arginine infusion (Arg), or their interaction $(\mathrm{D} \times \mathrm{A})$.

ever, there was still no effect of increased urea synthesis on liver $\mathrm{O}_{2}$ consumption. In sheep, increases in liver urea synthesis caused by mesenteric vein infusion of ammonia were not accompanied by significant changes in liver $\mathrm{O}_{2}$ consumption (Lobley et al., 1995, 1996; Milano et al., 2000). Similarly, ruminal or abomasal infusion of casein increased ammonia absorption and liver urea production in steers, but liver $\mathrm{O}_{2}$ consumption was not affected (Taniguchi et al., 1995). This suggests that the energy costs of the urea cycle are not as great as previously suggested (Huntington and Reynolds, 1987), particularly if the energy gain as a result of fumarate metabolism is accounted for (Newsholme and Leach, 1983; Waterlow, 1999). Assuming a net energy cost of 1 ATP per molecule of urea synthesized, and a gain of 6 ATP per molecule of $\mathrm{O}_{2}$ used (Newsholme and Leach, 1983), ureagenesis accounted for only $4.4 \%$ of liver $\mathrm{O}_{2}$ consumption $(3.6 \%$ and $5.2 \%$ when alfalfa and alfalfa plus urea were fed, respectively) in steers fed $\mathrm{N}$ far in excess of requirements. Whereas the present data are from maintenance-fed steers, these results suggest that the energy costs of feeding excess protein to ruminants (Tyrrell et al., 1970) are due to other factors than the energy costs of ureagenesis per se.

There was no apparent effect of feeding urea on the maximal potential contribution of gluconeogenic precursors to hepatic glucose production (Table 4). The combined hepatic removal of L-lactate and propionate accounted for an average of $65 \%$ of hepatic glucose synthesis. The remaining carbon required for glucose synthesis must have been derived from alternative gluconeogenic precursors, presumably AA and, to a lesser extent, glycerol, i-butyrate, and n-valerate. It is evident from data in Table 4 that the hepatic removal of potentially gluconeogenic free AA in plasma can account for virtually all the remaining fraction of hepatic glucose output (32 to $43 \%$ ), and that together, our measurements of net precursor removal could account for 97 to $118 \%$ of hepatic glucose production.

In general, arginine would not be considered an important precursor of glucose synthesis, but it can indirectly enter the gluconeogenic pathway at the level of 2-oxo glutarate through cleavage to ornithine and the subsequent transamination of the ornithine (Newsholme and Leach, 1983). However, similar to mesenteric vein infusion of L-alanine (Reynolds and Tyrrell, 1991b), arginine infusion did not affect the net hepatic production of glucose. Although the hepatic removal of AA and propionate was unaffected, the net hepatic removal and extraction of L-lactate was significantly increased by arginine when steers were fed the control diet (Table 3). The reasons for this response are unclear because there were no apparent arginine-induced changes in net hepatic urea or glucose synthesis specific to that particular diet. L-Lactate metabolism by the liver seems not only to be important in the provision of pyruvate but also for the maintenance of cytosolic reducing power (Krebs et al., 1979; Reynolds et al., 1992b). Therefore, the increase in hepatic removal of L-lactate during arginine infusion when the control diet was fed may have been in response to an increased requirement for $\mathrm{NADH}$ in the cytosol. However, there was also a trend for hepatic alanine removal to be increased on that diet (Maltby et al., 2005), which is in 
contrast to the observations of Reynolds and Tyrrell (1991b), who demonstrated that increasing the hepatic removal of alanine resulted in a simultaneous decrease in hepatic L-lactate removal. This result was assumed to be due to a shift in repartitioning between individual precursors of pyruvate. Therefore, because hepatic alanine flux showed a similar response to that of L-lactate, it suggests an increased requirement for pyruvate rather than a regulatory mechanism for $\mathrm{NADH}$ production.

\section{Hormones}

Pulse doses of arginine given intravenously have been used as an experimental tool for increasing jugular vein concentration of insulin, ST, and glucagon in both nonruminants and ruminants (Elsasser et al., 1986; Kuhara et al., 1991), although fewer studies have reported effects of i.v. arginine on peripheral glucagon concentrations in ruminants (Kuhara et al., 1991). In addition, there are relatively few studies reporting effects of chronic infusion of arginine i.v. or into the postruminal gut lumen on hormone concentrations in ruminants. Seven days infusion of arginine into the abomasum of lambs $(0.5 \mathrm{~g}$ of $\mathrm{Arg} \cdot \mathrm{HCl} / \mathrm{kg} \mathrm{BW}$; Davenport et al. 1990a) increased mean jugular vein concentrations of ST, but it did not alter jugular vein concentrations of insulin or $\mathrm{N}$ retention. In a companion study, heifers received $7 \mathrm{~d}$ abomasal infusions of arginine at two levels (0.33 and $0.50 \mathrm{~g}$ of $\mathrm{Arg} \cdot \mathrm{HCl} / \mathrm{kg} \mathrm{BW}$; Davenport et al. 1990b). In those heifers, both levels of arginine infusion increased $\mathrm{N}$ retention, but ST concentrations were only increased at the higher level of infusion, and insulin concentrations were not affected at either infusion rate. We used the low level of arginine infused into the abomasum of heifers (Davenport et al., 1990b) as the basis for the amount of arginine infused in the present study, arbitrarily assuming a 50\% recovery of abomasally infused arginine in the portal vein and aiming to manipulate the urea cycle without increasing ST concentrations. Although the interpretation of ST concentrations averaged across six samples at hourly intervals is limited relative to the information gained from analyzing individual samples obtained at frequent intervals (Elsasser et al., 1986; Davenport et al., 1990b), the data provide evidence that the level of arginine infused did not markedly affect average peripheral concentrations of ST. Similarly, chronic infusion of arginine into the abomasum of lactating cows (Vincini et al., 1988) and goats (Gow et al., 1979) had no effect on jugular vein concentration of ST.

In contrast to reported effects of arginine infused continuously into the abomasum (Vincini et al., 1988; Davenport et al., 1990a,b), continuous mesenteric vein infusion of arginine for $3 \mathrm{~d}$ increased arterial concentrations of insulin in the present study (Table 4). This increase in arterial insulin was due to the increase in PDV release of insulin and the fact that concomitant increases in net liver removal of insulin were not as great as the increase in PDV release. Although the resulting numerical increase in total splanchnic insulin release was not significant, it was likely to be sufficient to account for the increase in arterial insulin concentration and circulating pool size, especially if the response was at all refractory over the 3 -d infusion period. Whereas arginine is not metabolized by the pancreatic $\beta$-cell of the rat, it stimulates insulin secretion by a direct effect on polarization of the $\beta$-cell membrane (Morgan et al., 1988) and increases in insulin secretion in the present study are most likely attributable directly to measured increases in arterial arginine concentration (Maltby et al., 2005).

The elevation in arterial insulin concentration during arginine infusion provides an explanation for the significant decrease in arterial amino acid concentrations induced by infusing arginine (Maltby et al., 2005). Arginine infusion decreased $(P<0.10)$ the arterial concentration of $13 \mathrm{AA}$ and tended to decrease $(P<0.20)$ the arterial concentration of three more, while increasing $(P<0.01)$ arterial concentration of arginine and ornithine. Of 21 plasma AA measured, only arterial plasma concentrations of proline, citrulline, and lysine were not altered significantly by arginine infusion. These decreases in arterial AA concentration were not reflected by a change in urinary $\mathrm{N}$ excretion. Increases in urinary $\mathrm{N}$ excretion resulting from arginine infusion virtually equalled the amount of $\mathrm{N}$ infused (Maltby et al., 2005).

Although it is known that pulse doses of arginine stimulate pancreatic secretion and peripheral concentrations of glucagon in nonruminants (Assan et al., 1977) and peripheral concentrations of glucagon in ruminants (Kuhara et al., 1991), there are few reports of chronic infusion of arginine on peripheral glucagon concentrations in ruminants. In the present study, increases in arterial glucagon concentration during arginine infusion were attributable to increases in total splanchnic release (Table 3). Although increases in PDV release and hepatic removal of glucagon during arginine infusion were not significant due to large variations in measured net flux rates, increases in total splanchnic release of glucagon can only be the result of numerical increases in PDV release, which were greater than increases in liver removal. As for insulin, increases in PDV release of glucagon are likely to be the result of increased arterial arginine concentration. Although changes in liver removal of insulin and glucagon are in part attributable to alterations in portal supply, the regulation of liver removal of these hormones also seems to have a component that is independent of portal supply (Reynolds and Tyrrell, 1991a). Liver removal of insulin and glucagon was substantial, accounting for 48 and $86 \%$ of net PDV release, respectively. For glucagon, the rate of liver removal, both as a percentage of net PDV release and as a percentage of total supply (Table 5), was higher than previously reported for cattle (Reynolds et al., 1989; Reynolds and Tyrrell, 1991a). This high rate of hepatic glucagon removal may be at- 
tributable to the maturity of steers in the present study relative to their energy and $\mathrm{N}$ intakes (Reynolds et al., 1989).

Reasons for the decreased ST concentration and trend for increased glucagon concentration in arterial plasma when urea was fed (Table 3) are not certain, although it may be more than coincidence that glucagon is an important positive regulator of mitochondrial reactions of ureagenesis (Titheradge and Haynes, 1980; Waterlow, 1999), and ST decreases urea synthesis via both direct and indirect effects on hepatic urea cycle activity (Reynolds et al., 1992a). Total splanchnic release of glucagon tended to increase $(P<0.17)$ when urea was fed, and increases in total splanchnic glucagon release during arginine infusion were greater when urea was fed (Table 3 ). These changes in glucagon concentration and flux were associated with a greater arterial concentration of arginine when urea was fed (Maltby et al., 2005); however, arterial insulin concentration was not affected by diet, and arterial ST concentrations decreased. Others have demonstrated depressing effects of ammonia on insulin secretion and sensitivity (Visek, 1984), but no effects of increased ammonia absorption on insulin concentration, secretion, or release were measured in our study. It is possible that changes in arterial ST concentration are a result of changes in metabolism by the kidneys (Hammerman, 1989) or other body tissues.

In conclusion, increased net absorption of ammonia or arginine had little effect on net splanchnic metabolism of glucose, $\mathrm{O}_{2}$, or other nonnitrogenous nutrients in mature beef steers fed alfalfa-based diets at maintenance. Chronic increases in arginine absorption at physiological levels increased arterial concentrations of insulin and glucagon but not ST. In addition, feeding urea decreased arterial ST concentration and tended to increase arterial glucagon concentration, responses which would enhance liver ureagenesis. These data suggest that production costs of feeding excess protein or nonprotein $\mathrm{N}$ to ruminants are not attributable to effects of increased urea synthesis per se on liver metabolism of glucose, $\mathrm{O}_{2}$, or nonnitrogenous energy substrates.

\section{Implications}

Excess ruminally degradable protein intake increases ammonia absorption, and it is often associated with a decrease in the efficiency of dietary nitrogen and energy utilization. In part based on the gross energy requirement of the urea cycle, it is often assumed that excess ammonia absorption decreases the efficiency of energy utilization through increased hepatic oxygen use and decreased glucose synthesis. The present study does not support this assumption. In maintenance-fed beef steers, increases in liver urea synthesis caused by increasing ammonia or arginine absorption had no effect on liver oxygen consumption or glucose synthesis. Increased ammonia absorption decreased the plasma concentration of somatotropin, which decreases urea synthesis, and tended to increase plasma concentration of glucagon, which stimulates urea synthesis. This suggests these hormones are sensitive to changes in ammonia absorption and have a role in regulating ammonia metabolism via the urea cycle.

\section{Literature Cited}

Assan, R., J. R. Attali, G. Ballerio, J. Boillot, and Girard J. R. 1977. Glucagon secretion induced by natural and artificial amino acids in the perfused rat pancreas. Diabetes 26:300-307.

Bergman, E. N. 1990. Energy contributions of volatile fatty acids from the GI tract in various species. Physiol. Rev. 70:567-590.

Bruggemann, J., and D. Giesecke. 1967. The effects of urea on rumen microbiology and metabolism. Pages $125-154$ in Urea as a Protein Supplement. M. E. Briggs, ed. Pergamon Press, Oxford, U.K.

Chalupa, W., J. Clark, P. Opliger, and R. Lavker. 1970. Ammonia metabolism in rumen bacteria and mucosa from sheep fed soy protein or urea. J. Nutr. 100:161-169.

Davenport, G. M., J. A. Boling, and K. K. Schillo. 1990a. Nitrogen metabolism and somatropin secretion in beef heifers receiving abomasal arginine infusions. J. Anim. Sci. 68:1683-1692.

Davenport, G. M., J. A. Boling, K. K. Schillo, and D. K. Aaron. 1990b. Nitrogen metabolism and somatrophin secretion in lambs receiving arginine and ornithine via abomasal infusion. J. Anim. Sci. 68:222-232.

Demigne, C., C. Yacoub, and C. Remesy. 1991. Interactions between propionate and amino acid metabolism in isolated sheep hepatocytes. Br. J. Nutr. 65:301-312.

Elsasser, T. H., A. C. Hammond, T. S. Rumsey, and R. Fayer. 1986. Perturbated metabolism and hormonal profiles in calves infected with Sarcocystic cruzi. Domest. Anim. Endocrinol. 3:277-287.

Fernandez, J. M., W. J. Croom, L. P. Tate, and A. D. Johnson. 1990. Subclinical ammonia toxicity in steers: Effects on hepatic and portal-drained visceral flux of metabolites and regulatory hormones. J. Anim. Sci. 68:1726-1742.

Gow, C. B., S. S. E. Ranawana, R. C. Kellaway, and G. H. McDowell. 1979. Responses to post-ruminal infusions of casein and arginine, and to dietary protein supplements in lactating goats. Br. J. Nutr. 41:371-382.

Hammerman, M. R. 1989. The growth hormone-insulin-like growth factor axis in the kidney. Am. J. Physiol. 257:F503-F514.

Huntington, G. B., and C. K. Reynolds. 1987. Oxygen consumption and metabolite flux of bovine portal drained viscera and liver. J. Nutr. 117:1167-1173.

Krebs, H. A., P. Lund, and M. Stubbs. 1979. Interrelations between gluconeogenesis and urea synthesis. Pages 269-291 in Gluconeogenesis: Its Regulation in Mammalian Species. R. Hanson and M. A. Mehlan, ed. Wiley and Sons, New York.

Kuhara, T., S. Ikeda, A. Ohneda, and Y. Sasaki. 1991. Effects of intravenous infusion of 17 amino acids on the secretion of GH, glucagon and insulin in sheep. Am. J. Physiol. 260(Endocrinol. Metab. 23):E21-E26.

Lobley, G. E., A. Connell, M. A. Lomax, D. S. Brown, E. Milne, A. G. Calder, and D. A. H. Farringham. 1995. Hepatic detoxification of ammonia in the ovine liver: Possible consequences for amino acid catabolism. Br. J. Nutr. 73:667-685.

Lobley, G. E., P. J. M. Weijs, A. Connell, A. G. Calder, D. S. Brown, and E. Milne. 1996. The fate of absorbed and exogenous ammonia as influenced by forage or forage-concentrate diets in growing sheep. Br. J. Nutr. 76:231-248.

Maltby, S. A., C. K. Reynolds, M. A. Lomax, and D. E. Beever. 2005. Splanchnic metabolism of nitrogenous compounds and urinary nitrogen excretion in steers fed alfalfa under conditions of increased absorption of ammonia and L-arginine supply across the portal-drained viscera. J. Anim. Sci. 83:1075-1087.

Meijer, A. J., J. A. Gimpel, G. Deleeuw, M. E. Tischler, J. M. Tager, and J. R. Williamson. 1978. Inter-relationships between glucone- 
ogenesis and ureagenesis in isolated hepatocytes. J. Biol. Chem. 253:2308-2320.

Milano, G. D., Hotston-Moore, A., and G. E. Lobley. 2000. Influence of hepatic ammonia removal on ureagenesis, amino acid utilization and energy metabolism in the ovine liver. Br. J. Nutr. 83:307-315

Morgan, L. M., P. R. Flatt, and V. Marks. 1988. Nutrient regulation of the entero-insular axis and insulin secretion. Nutr. Res. Rev. 1:79-97.

Newsholme, E. A., and A. R. Leach. 1983. Amino acid metabolism. Page 382 in Biochemistry for the Medical Sciences. J. Wiley and Sons, London, U.K.

Prior, R. L. 1976. Effects of dietary soy or urea nitrogen and feeding frequency on nitrogen metabolism, glucose metabolism and urinary metabolite excretion in sheep. J. Anim. Sci. 42:160-167.

Prior, R. L., J. A. Milner, and W. J. Visek. 1972. Carbohydrate and amino acid metabolism in lambs fed purified diets containing urea or isolated soy protein. J. Nutr. 102:1223-1232.

Reynolds, C. K., and D. F. Hucht. 1994. Effects of mesenteric vein L-ornithine infusion on liver metabilism in beef steers. J. Anim. Sci. 72(Suppl. 1):241. (Abstr.)

Reynolds, C. K., G. B. Huntington, T. H. Elsasser, H. F. Tyrrell, and P. J. Reynolds. 1989. Net metabolism of hormones by portaldrained viscera and liver of lactating holstein cows. J. Dairy Sci. 72:1459-1468.

Reynolds, C. K., H. Lapierre, H. F. Tyrrell, T. H. Elsasser, R. C. Staples, P. Gaudreau, and P. Brazeau. 1992a. Effects of growth hormone-releasing factor and feed intake on energy metabolism in growing beef steers: Net nutrient metabolism by portaldrained viscera and liver. J. Anim. Sci. 70:752-763.

Reynolds, C. K., and H. F. Tyrrell. 1991a. Effects of diet composition and intake on visceral insulin and glucagon metabolism in cattle. Pages 12-15 in Energy Metabolism of Farm Animals. EAAP Publ. No. 58. C. Wenk and M. Boessinger, ed. ETH-Zentrum, Zurich, Switzerland.

Reynolds, C. K., and H. F. Tyrrell. 1991b. Effects of mesenteric vein L-alanine infusion on liver metabolism in beef heifers fed diets differing in forage to concentrate ratio. J. Anim. Sci. 66:437-450.
Reynolds, C. K., H. F. Tyrrell, and L. E. Armentano. 1992b. Effects of mesenteric vein n-butyrate infusion on liver metabolism by beef steers. J. Anim. Sci. 70:2250-2261.

Reynolds, C. K., H. F. Tyrrell., and P. J. Reynolds. 1991a. Effect of diet forage-to-concentrate ratio and intake on energy metabolism in growing beef heifers: Net nutrient metabolism by visceral tissues. J. Nutr. 121:1004-1015.

Reynolds, C. K., H. F. Tyrrell, and P. J. Reynolds. 1991b. Effect of diet forage-to-concentrate ratio and intake on energy metabolism in growing beef heifers: Whole body energy and nitrogen balance and visceral heat production. J. Nutr. 121:994-1003.

Seal, C. J., D. S. Parker, and P. J. Avery. 1992. The effect of forage and forage-concentrate diets on ruminal fermentation and metabolism of nutrients by the mesenteric and portal-drained viscera in growing steers. Br. J. Nutr. 67:355-370.

Spires, H. R., and J. H. Clark. 1979. Effect of intra-ruminal urea administration on glucose metabolism in dairy steers. J. Nutr. 109:1438-1447.

Taniguchi, K., G. B. Huntington, and B. P. Glenn. 1995. Net nutrient flux by visceral tissues of beef steers given abomasal or ruminal infusion of casein or starch. J. Anim. Sci. 73:236-249.

Titheradge, M. A., and R. C. Haynes. 1980. The hormonal stimulation of ureagenesis in isolated hepatocytes through increases in mitochondrial ATP production. Arch. Biochem. Biophys. 201:44-55.

Tyrrell, H. F., P. W. Moe, and W. P. Flatt. 1970. Influence of excess protein intake on energy metabolism of the dairy cow. Pages 69-72 in Energy Metabolism of Farm Animals. EAAP Publ. No. 13. A. Schurch and C. Wenk, ed. Juris Druck \& Verlag Zurich, Zurich, Switzerland.

Vicini, J. L., J. H. Clark, W. L. Hurley, and J. M. Bahr. 1988. Effects of abomasal or intravenous administration of arginine on milk production, milk composition, and concentrations of ST and insulin in plasma of dairy cows. J. Dairy Sci. 71:658-665.

Visek, W. J. 1984. Ammonia: Its effects on biological systems, metabolic hormones and reproduction. J. Dairy Sci. 67:481-498.

Waterlow, J. C. 1999. The mysteries of nitrogen balance. Nutr. Res. Rev. 12:25-54. 